The University of Maine

DigitalCommons@UMaine

Publications

Senator George J. Mitchell Center for Sustainability

Solutions

$1-2015$

\title{
The Maine Tidal Power Initiative: Transdisciplinary sustainability science research for the responsible development of tidal power
}

Jessica Spelke Jansujwicz

University of Maine, jessica.jansujwicz@maine.edu

Teresa R. Johnson

University of Maine

Follow this and additional works at: https://digitalcommons.library.umaine.edu/ mitchellcenter_pubs

\section{Repository Citation}

Jansujwicz, Jessica Spelke and Johnson, Teresa R., "The Maine Tidal Power Initiative: Transdisciplinary sustainability science research for the responsible development of tidal power" (2015). Publications. 11.

https://digitalcommons.library.umaine.edu/mitchellcenter_pubs/11 
The Maine Tidal Power Initiative: Transdisciplinary sustainability science research for the responsible development of tidal power

Jessica Spelke Jansujwicz, Teresa R. Johnson

J. S. Jansujwicz and T. R. Johnson University of Maine, Orono, ME, USA

e-mail: jessica.jansujwicz@maine.edu

Keywords Transdisciplinary, Interdisciplinary, Collaboration, Stakeholder engagement, Renewable energy, Tidal power 
Abstract

The Maine Tidal Power Initiative (MTPI), an interdisciplinary team of engineers, marine scientists, oceanographers, and social scientists, is using a transdisciplinary sustainability science approach to collect biophysical and social data necessary for understanding interactions between human and natural systems in the context of tidal power development in Maine. MTPI offers a unique opportunity to better understand how group structure and process influence outcomes in transdisciplinary sustainability science research. Through extensive participant observation and semi-structured interviews we: (1) describe MTPI's organizational structure; (2) examine MTPI's research approach and engagement with stakeholders from different sectors of society (i.e., industry, government, and the local community); and (3) identify challenges and opportunities for involving different disciplinary expertise and diverse stakeholders in transformational sustainability science research. We found that MTPI's holistic mission, non-hierarchical structure, and iterative stakeholder engagement process led to important benefits and significant challenges. Positive outcomes include knowledge development, a transferable research framework, shared resources, personal reward, and a greater understanding of the local environment and community. Challenges identified include balancing diverse interests and priorities, maintaining engagement, managing stakeholder relationships, and limited resources. Lessons learned from the process of integrative collaborative research in Maine can offer guidance on what should be considered when carrying out similar transdisciplinary sustainability science projects in other research contexts. 
Introduction

Transformational sustainability science research is concerned with generating actionable knowledge, incorporating knowledge from outside academia, and dealing with different values and political interests (Weik et al. 2012b; Clark and Dickson 2003). Fundamentally, this requires a significant change in the way knowledge is produced and used in support of practical solutions to pressing sustain-ability problems (Komiyama and Takeuchi 2006). Most notable is an increased emphasis on the co-production of knowledge and the inclusion of stakeholders in all phases of the research and implementation process (Hart and Bell 2013; Anderson et al. 2012; Kates et al. 2001). Collaboration and partnerships with and across different stakeholder groups are considered critical to sustainability science (Kates et al. 2001; Blackstock et al. 2007; Spangenberg 2011; Talwar et al. 2011; Weik et al. 2012a), and partnerships are supported as a means for transformational change (Weik et al. 2012a, b; Clark and Dickson 2003). This requires that scientists continuously engage with a broad range of stakeholders, not only to collectively identify and understand sustainability problems in coupled human-environment systems, but also to develop joint and coordinated solutions to these problems (van Kerkhoff and Lebel 2006; Weik et al. 2012b; Clark and Dickson 2003).

With a focus on how society and the scientific community are engaged in identifying and structuring problems for research, a participatory, transdisciplinary research approach supports a transformational sustainability science agenda. 
The term transdisciplinary describes "research that addresses the knowledge demands for societal problem solving regarding complex societal concerns" (Hirsch Hadorn et al. 2006, p. 122). Fundamental to the process of transdisciplinary research is: (1) the generation of solutions-oriented knowledge that is continuously integrated into both scientific and societal practice (Lang et al. 2012; Hirsch Hadorn et al. 2006) and (2) the engagement of relevant interests in the research process (Talwar et al. 2011; Blackstock et al. 2007). Such a holistic approach requires the ability of scientists to transgress disciplinary boundaries and pre-conceptions and takes into account the knowledge of people involved and their needs and interests at stake (van Kerkhoff 2013; Hirsch Hadorn et al. 2006). As an integrative and reflexive approach, transdisciplinary research encourages continuous interaction between scientists from different disciplines (from within academia and other research institutions) and different practice actors including stakeholders from industry or the general public (Lang et al. 2012; Komiyama and Takeuchi 2011). This participatory process is thought to facilitate mutual learning and empower stakeholders to contribute more actively to implementation or in related decision-making processes (Lang et al. 2012; Bell et al. 2013). At issue, however, is translating these idealized principles into effective practice.

In theory, a transdisciplinary approach is a logical framework for decision making and action. In practice, developing a methodology of integrative research is a difficult task, and scholars are faced with significant challenges. For example, van Kerkhoff (2013) notes, "researchers seeking to 'do integrative research' as a fundamental aspect of sustainability science confront a bewildering 
array of case studies, methods, conceptual frameworks and diverse interpretations." Similarly, Lang et al. (2012) find that the literature is fragmented and dispersed and does not provide good guidance to researchers and practitioners on what can be learned from different approaches and what needs to be considered when carrying out transdisciplinary sustainability science. This points to the fundamental challenge of developing a framework for interdisciplinary research and stakeholder engagement that is specific enough to offer guidance for a particular project, yet broad enough to be transferable to a wide range of problems, perspectives, and contexts that characterize complex sustainability problems (van Kerkhoff 2013). In an effort to fill this gap, this paper contributes to a better understanding of transdisciplinary sustainability science research in the context of renewable energy development.

In this paper, we present lessons learned from a transformational sustainability science research program for the responsible development of tidal power in Maine. Our intent is not to provide a comprehensive set of principles for guiding transdisciplinary sustainability research, but rather to draw on empirical research and our experience to present exemplary opportunities and challenges faced in a concrete project. Such research on the research allows us to understand the outcomes of transdisciplinary sustainability research from the perspectives of the researchers and stakeholders involved, with the goal of using lessons learned to change future practice in sustainability science. Because of a focus on problem identification and analysis (i.e., how biological, social, and technical system research components interact) and on problem solving (i.e., the implications of these interactions for decision making and moving new technologies forward in 
a responsible way), tidal power research in Maine offers an ideal case study for understanding and informing the process of transdisciplinary sustainability science research.

We focus on research and decision making in the context of new technologies designed to capture energy from the natural movement of the tides, generally referred to as marine hydrokinetic (MHK) energy. MHK technologies are new, and so there have been few opportunities to evaluate their environmental and social impacts. While studies are forthcoming (Viehman and Zydlewski 2014; Viehman et al. 2014), only a few devices have been deployed and tested in rivers and oceans, and even fewer environmental studies of these technologies have been completed (Cada et al. 2007, 2012). Thus, there are currently little scientific data with which to inform policy and permitting decisions (Shields et al. 2011). Uncertainties in the development and permitting process for new tidal technologies may pose significant environmental, social, and economic challenges for different stakeholder groups (Jansujwicz and Johnson 2013). Approaches aimed at understanding and informing these concerns by generating actionable knowledge and incorporating knowledge from diverse stakeholders is necessary to contribute to a sustainable energy transition.

In response to the growing demand for knowledge necessary to develop Maine's unique tidal resource, an interdisciplinary team of engineers, biologists, oceanographers, and social scientists from the University of Maine and Maine Maritime Academy, organized as the Maine Tidal Power Initiative (MTPI), is collaborating with tidal power developers, state and federal regulators, 
and the local community to promote responsible development of this renewable energy resource. In examining MTPI, we focus on how group structure and process lead to positive outcomes and substantive challenges. Specifically, we are interested in the process by which knowledge is produced, shared, and used to address societal concerns related to tidal energy development in Cobscook Bay, Maine, the site of the first grid-connected MHK project in the Americas. To this end, our research has three primary objectives: (1) describe MTPI's organizational structure; (2) examine MTPI's research approach and engagement with stakeholders from different sectors of society (i.e., industry, government, and the local community); and (3) identify challenges and opportunities for involving different disciplinary expertise and diverse stakeholders in transformational sustainability science research within the context of tidal energy development in Maine. We share lessons learned from MTPI's process of integrative collaborative research and suggest what should be considered when carrying out similar transdisciplinary sustainability science projects in other renewable ocean energy contexts.

Study Background

Since 2009, MTPI engineers, marine scientists, oceanographers, and social scientists have been using a transdisciplinary approach to collect biophysical and social data necessary for understanding interactions between human and natural systems in the context of tidal energy development in Maine. To date, research has focused on Ocean Renewable Power Company's (ORPC's) Cobscook Bay Tidal Energy Project (CBTEP). In 2005, ORPC began working with federal and 
state agencies to secure the necessary approvals to construct and operate the CBTEP near Eastport and Lubec, Maine. Cobscook Bay lies at the entrance to the Bay of Fundy where the mean tidal range is about 6 meters (Brooks 2004). Upon obtaining the Federal Energy Regulatory Commission (FERC) pilot license in 2012, the CBTEP became the first MHK project within the U.S. to gain approval to connect to the interstate power grid.

The MTPI brings together multiple disciplines and integrated research components to understand and inform the CBTEP (Johnson and Zydlewski 2012). MTPI's sea-floor geomechanics team is researching options for efficient and robust foundations for both fixed-bottom and floating tidal energy devices (Landon Maynard et al. 2013). Local information about sediment types is used to consider complex lateral loading from currents, scour, and sediment transport around foundations using experimental modeling. MTPI's resource assessment team is researching the commonality and uniqueness of targeted MHK developments worldwide. Water current data collected at specific sites are used with modeling methods to assess MHK tidal resources, documenting the accuracy and uncertainties associated with different methods and assessing the impacts of energy extraction on hydrodynamics (Xu and Xue 2011). The turbine engineering team is characterizing baseline MHK systems to provide industry benchmarks to evaluate and compare emerging turbine technology with regard to energy extraction performance. This focus includes laboratory design and testing of standard turbine types and development of experimentally validated design codes (Urbina et al. 2013). The fish assessment team is using multiple gear types and approaches deployed at the site of the CBTEP and a control site to determine the effects of MHK devices on fish, particularly their behavior and water column distribution (Viehman and 
Zydlewski 2014). The human dimensions team is investigating public perception, social acceptability, cooperative research, stakeholder engagement, and the regulatory and permitting process for MHK development. The social science research presented here is one part of MTPI's larger human dimension research program.

Methods

To better understand the structure, process, and outcomes of MTPI's transformational sustainability science research approach, we used qualitative social science research methods including extensive participant observation, semi-structured interviews, and document review (Bernard 2006). Our research on the research approach involved immersion in the MTPI research under examination to distil lessons learned from empirical research and our own observations. This so-called emic/etic approach (DeWalt and DeWalt 2011) provides greater insight because it looks at the research from the point of view of both the researcher and the other MTPI scientists and stakeholders.

We observed over 40 MTPI bi-monthly team meetings of MTPI scientists and partners from industry, consulting, and the non-profit sector. Between February 2011 and June 2013, we organized and participated in six community meetings with local fishermen and community members in Eastport and Lubec. The purpose of these meetings was threefold: (1) to gather local 
knowledge to inform MTPI's fish assessment team research in Cobscook Bay, (2) to share MTPI research with the larger community, and (3) to provide an opportunity to listen to and document community concerns, questions, and information needs. In fall 2012, we organized and participated in a daylong MTPI technical meeting for stakeholders in industry, federal, state, and local government, and the local community. In addition to hosting meetings, we also attended meetings that occurred as a part of the regulatory and permitting process including two U.S. Coast Guard public meetings, several agency-developer consultation meetings, and two ORPC Adaptive Management Team (AMT) meetings. ORPC's AMT was organized as part of the company's permitting process and is comprised of technical advisors from the federal and state government and academic and non-academic researchers with expertise in marine mammals and fish biology. We attended the Cobscook Bay Tidal Energy Fair in Eastport, a public event hosted by ORPC. Detailed field notes were taken during all meetings and events. When possible meetings were audio recorded and transcribed, meeting minutes and handouts were reviewed to supplement our observations.

Between 2010 and 2012, we conducted 22 semi-structured interviews with MTPI scientists and partners. MTPI scientists included faculty, graduate and undergraduate students, and research staff. To preserve confidentiality, we do not differentiate type of researcher, but rather group them under the general label of "MTPI scientists." Interviews with MTPI scientists and partners lasted around $1 \mathrm{~h}$ and followed a general question guide. Questions covered the participant's expertise related to tidal energy development; expected outcomes in connection with their work; perspectives on the mission of MTPI; and questions about their specific involvement in MTPI, 
including who they interacted with and how their research linked with other MTPI research efforts. We also asked participants what they perceived as positive aspects of working on MTPI and about the challenges they faced. With the exception of one, interviews were recorded and transcribed. In addition to semi-structured interviews, we had numerous informal interviews and discussions with MTPI researchers and stakeholders throughout the research process. These interactions were recorded in extensive field notes.

Interview transcripts, public meeting transcripts, and field notes from meetings were entered into the QSR-NVivo 10 database for organization and qualitative analysis. For analysis, we used a modified grounded theory approach (Glaser and Strauss 1967; Strauss and Corbin 1990) that focused on identifying themes, patterns, and relationships emerging in the data through an iterative process of coding and recoding throughout the project. First cycle coding (Saldaña 2009) consisted of in vivo codes taken directly from the data (Charmez 2006) and a priori codes drawn from existing theory and our early observations. As we progressed toward second cycle coding, coding categories were constantly compared and coded data were rearranged and reclassified into different or new categories or refined subcategories (Saldaña 2009). Throughout the coding process, we used analytical memos to reflect on and write about the study's research questions, code choices and operational definitions, emergent themes, patterns, and concepts, possible connections or links among codes, patterns, categories, themes, and concepts, and emergent or related existing theory (Glaser and Strauss 1967; Saldaña 2009). We also used memos to reflect on our own experiences as MTPI researchers. The final stages of our analysis focused on how themes and concepts systematically interrelated and either led toward development of original theory to 
explain our research findings (Corbin and Straus 2008) or to preexisting theories or studies that could explain the patterns, themes, and concepts emerging from our data. Here, we present on themes related to MTPI structure, process, and outcomes.

$\underline{\text { Results }}$

MTPI organizational structure

MTPI is described as a "purposefully loosely organized, diverse group of scientists aimed at advancing knowledge pertinent to MHK development." Core research tasks are divided among the four disciplinary teams (Engineering, Environmental Assessment, Resource Assessment, Human Dimensions) (Fig. 1). One scientist is generally recognized as being the primary contact, however, leadership is shared among disciplinary team leaders and decisions are made largely as a group. Each team is led by a single faculty member and includes postdocs, research associates, technicians, graduate and undergraduate students. Academic researchers from the University of Maine and the Maine Maritime Academy comprise the core membership of MTPI, but they work closely with an industry consultant.

Generally, MTPI's structure is described as a "coordinated effort to bring multiple disciplinary expertise together to address various aspects of tidal power development." Rather than 
focus solely on environmental impacts (i.e., effects on fish) or "typical kinds of engineering research," MTPI is viewed as "a whole team of multiple biologists, multiple engineers, multiple social scientists" focused on social, physical, and environmental aspects of tidal energy. Describing this "holistic" approach, one scientist said, "The engineering development side, the energy extraction side...the social side of energy development... the nice thing about MTPI is that those have gone hand in hand." Another said, "The strongest point of MTPI is that it's been the only organization l've seen in the world on tidal energy that's itself set up to address all the pieces of tidal energy development."

As an organization, MTPI's structure is described as "non-hierarchical." To illustrate, when asked by a colleague how MTPI was structured, one of the scientists responded, 'Structure!?! What are you talking about??' She continued, "I think having that informal structure, to me, was actually refreshing and it gave everybody a voice, and it wasn't hierarchical."

Although generally informal and loosely organized, certain formal organizational elements were identified as important unifying characteristics. These include MTPI's "name" and "mission statement." Additional formal components include two established memorandum of understanding (MOUs) with international research partners at Hirosaki University (Japan) and Acadia University (Canada). 


\section{Process}

Interdisciplinary collaboration

Interdisciplinary collaboration was identified as a key aspect of MTPI's overall approach. Collaboration among scientists from different disciplinary teams is facilitated by weekly (then beginning in 2012, bi-monthly), MTPI meetings. The primary purpose of these 1-h meetings is to share individual team research, receive feedback, plan MTPI events, compile progress reports, or explore potential funding and partnership opportunities. Individual MTPI research teams also meet outside of the larger MTPI meetings, and one scientist described these "regular meetings" with staff as "just as important as the larger MTPI meeting" for "getting the work done." MTPI scientists serve as co-advisors for MTPI graduate and undergraduate students, and this provides additional opportunity for collaboration and interaction across teams.

Stakeholder engagement

Communication with stakeholders was identified as an important strength of MTPI. According to one scientist, the group's "focus on sharing research with stakeholders-in the hydrokinetic industry, in the regulatory community, and in the public at large - makes [MTPI] 
unique." Engagement with developers, regulators, and community stakeholders occurs throughout the research process using different methods of formal and informal engagement (Fig. 2).

Engagement with ORPC began early in the development process when the company first began formulating plans for the CBTEP and identified the need to consider the potential impacts of their activities on fishes from both a technical and permitting perspective. Since that time, MTPI's regularly scheduled meetings have provided a mechanism for continuous interaction. Meetings provide an opportunity for research and development project updates.

Other formal engagement mechanisms include agency-developer consultation meetings (organized as a part of the MHK permitting process), ORPC Adaptive Management Team meetings (every 6 months), and technical symposiums hosted by MTPI in 2012 and 2013. Engagement with regulators is also facilitated through the distribution of technical research reports. MTPI scientists compile and share reports with regulators and this process provides an opportunity for agencies to comment on the research results. In describing these interactions, one scientist said, "We would always answer [the regulator's] questions. I'm sure that's going to [happen] more and more as the device is in the water, as we're collecting information." Informally, ORPC staff and MTPI scientists interact while in the community. ORPC has a staffed office in Eastport and scientists are on-site several times a year for research and outreach activities. 
Engagement with community stakeholders including fishermen and local business owners occurred throughout the research process. A series of community meetings were collaboratively organized by the human dimensions and fish assessment teams to engage fishermen and other community members in MTPI's fish assessment work. To date, there was limited information available on community fish populations in the bay, and the idea was to tap into local fishermen's ecological knowledge to inform community fish sampling protocols. Additional meetings held in both Eastport and Lubec were organized at different points in the research process to share MTPI research and receive feedback from the general community including local fishermen, business owners, and seasonal and permanent residents. Through these public meetings researchers indicated that they are: "not just communicating [their] research... but asking for [community] input to [the] research." MTPI scientists indicated that producing information to "inform the community" was important, but so was "find[ing] some way to get the information back to them in a way that they can use it." In addition, MTPI is "reaching out" through the local newspapers, email, and Twitter to let the community know when they will be in the area, where they will be conducting studies, and what types of studies they will be doing. Informal methods of engagement include "hands-on" interactions with the local community, particularly fishermen and local business owners while conducting fish assessment research in Cobscook Bay. One scientist said, "When we're physically there, we interact an awful lot." This includes "chance meetings at the docks" with fishermen or conversations in local coffee shops and restaurants. The fish assessment team also hires local contractors to assist with their field research, including boat captains to help with acoustics and trawling. 
In addition to sharing research with industry, regulatory, and community stakeholders, MTPI scientists also engage with a growing network of international researchers. Methods of engagement include conferences and workshops (including one international symposium hosted by MTPI). Generally, the purpose of these meetings is to share research approaches, technical advice, and preliminary findings.

\section{Outcomes}

Knowledge development

An important outcome of MTPI's interdisciplinary research is baseline data to inform the development process and facilitate growth of the industry at multiple scales (commercial and small sites/community). MTPI is perceived (by partners) to be an important resource for technical information regarding the potential effects of tidal energy development (i.e., the "science"). They are considered an "independent" source of "non-biased expertise" and are viewed as "noncommercial" and "less partial" than private developers. MTPI scientists consider "knowledge development" an important aspect of MTPI's mission, and they view their role as information providers. One scientist said, "The mission of MTPI is to be an honest broker from an informational standpoint." In this role, MTPI "support(s) companies" with the different expertise they "bring to the table." MTPI scientists 
are also "providing what [they] hope is unbiased information to ORPC to communicate to the regulators." This information enables regulators to "speak back to the laws they had to address."

Knowledge developed for the CBTEP is also informing proposed projects and research in other renewable energy contexts. For example, at the international level, MTPI is working collaboratively with researchers from Hirosaki University, University of Tokyo, and the North Japan Research Institute for Sustainable Energy (NJRISE) to discuss tidal power development and research opportunities in Aomori Prefecture, Japan. Through international meetings and technical workshops, MTPI scientists aim:

...To get most of the information that's being collected on marine renewable energy out into the public domain.... There's a lot that some of the industries are holding back that they don't want to share that are not like ORPC. The idea is to try make some of this, in whatever form everybody's comfortable with, available so that the whole industry can move forward.

Research framework

A second identified outcome of MTPI's approach is a generalized research framework that can be used to inform regulatory and permitting decisions in Maine and beyond. By developing a "model" that can be applied to other places, including a new site that ORPC is trying to permit in 
Western Passage, outside Cobscook Bay, MTPI scientists hope to inform ORPC "from a larger perspective." In the view of a scientist, MTPI is potentially developing a "better integrated approach" to research that could transcend any particular site or project. They said:

If we could have a framework and say, 'These are the things that have to be considered when you're considering tidal power'... You need to know what the resource is, you need to know how you're going to capture it, you need to know what is going to be affected by it, including the human part of that. What is the framework that can be used from a scientific perspective to answer those questions anywhere?

Community engagement

MTPI scientists identified beneficial outcomes associated with "really close intense interaction" with community stakeholders. As an example, a scientist said, "... being able to sit on a boat with people from the community is very helpful to us understanding how the community works and how we might be effective or helpful in communicating to them what we're doing." Another said, "Getting their feedback into the process during when we're contracting them is important." For some scientists, these interactions have helped to "build a comfort level over time" and have enabled them to learn more about the area and fisheries from "local experts of Cobscook Bay." "Chance meetings at the docks" with fishermen and other informal interactions have increased visibility and interest in the team's fish assessment research. A scientist working in 
Cobscook Bay said: "When we go down to the breakwater to put gear on a boat, if there are other fishermen coming and going, many of them will at least say hello." The scientist further described:

...when they see us wearing waders looking like two crazy guys with a net in Cobscook Bay, they usually stop and ask what the heck we're doing. They always seem to find it pretty interesting. Hopefully we catch a fish and we say oh, this is...People are interested. People want to know what's out there.

Another scientist described conversations at local shops and restaurants:

It's at a point now where we could go into some places, some stores or restaurants, and the wait staff will recognize us and say, 'Oh, I see you're back' and that sort of thing. Those are just casual observations or encounters, but at least they recognize 'Oh, those are the folks from the University of Maine.'

Shared resources

ORPC developers identified beneficial outcomes of collaborating with MTPI. For example, they thought that the University "could make things happen quicker" than the private sector. Because MTPI and the University were considered a "separate independent entity," they were (in the view of the developer), "able to attract money for pools that nobody else can play in." One 
ORPC developer acknowledged, "We as a company benefit from having that work done for us, and we didn't have to go out and get a million dollars to do all the work."

Personal reward

Many of the scientists spoke of the personal benefits of collaboration as an important outcome of their involvement with MTPI. In general, scientists and partners shared positive views of MTPI's integrative and multidisciplinary "philosophy" and "working together on totally separate things towards a common goal." One partner said:

This is hard stuff to have just the collaboration and encouragement... you need a certain amount of energy just to move things forward, so you've brought together bright, interested people who can hold meetings, get papers out and reports. It's a concerted effort and it's more effective.

Scientists appreciated the opportunity to interact with researchers outside of their own discipline or specialized area of expertise. Reflecting on her experiences, one scientist commented:

That's the thing that's really attractive to me about MTPI. I get to interact and interface not just with engineers who are focused on the turbine... but I have a direct link with, 'Here's the science that we are doing to protect the environment, and here's the science that we're doing in order to increase people's awareness'. 
Scientists and partners indicated that they had their "eyes opened by some other discipline" and collaboration gave them "additional ways to think about what they are doing." One scientist said:

Being able to sit down once a week and listen to engineers and social scientists and civil engineers, and other biologists, and so on, it's a new per-spective...That's been fun because it's a group of colleagues around campus that I wouldn't normally sit down with. That's definitely a positive thing.

Scientists felt that MTPI offered a broad view of the entire process and where their specific research and interests "actually fit." One said:

Certainly from a person who's participating in this project, I have a greater understanding of what everyone else is doing and all of the other things that go into development...From a personal level, having the interaction and understanding all the barriers to development that are not just technical.... The best thing that I get out of it is the breadth of knowledge and interest of all the group together.

Scientists noted that collaboration took considerable time and effort, but that they valued what was described as the "aha" moments. To explain, one scientist said: 
As much as you sit through hours of potentially not understanding what people are talking about, or trying to communicate and making sure you're staying on the same page, it's the reward in the end of seeing the connections.

\section{Challenges}

In addition to positive outcomes, MTPI scientists and partners identified four key challenges that arose from implementing the group's holistic mission and comprehensive approach. These include (1) balancing interested and priorities; (2) maintaining participation and engagement; (3) managing stakeholder relationships; and (4) limited resources.

When asked what they perceived as some of the challenges of working on the MTPI, one scientist replied, "I think the differences in perspective can be a great thing, but maybe there's some growing pains as folks try to figure out where the groups should be going and if they agree." This challenge of balancing interests and priorities prompted one scientist to ask, "How can our group continue to work as a group and not splinter into our basic disciplines?" MTPI became more difficult to manage as the research evolved. One scientist explained, "The weekly meetings we're having all of a sudden, the engineers were meeting before us, and then we were meeting together, and it got more complicated." Many scientists and partners thought that MTPI meetings were too 
"bogged down" in the "dayto-day" logistics, and "that turned people off." As meetings became less frequent, however, one scientist acknowledged:

Making sure that all the folks involved stay engaged, I think that's important. That takes communication. As much as the whole idea of meeting a lot is sometimes overwhelming, I think it's really important. Sometimes people don't want to meet, and we stopped meeting recently, and I think that's a real challenge because we are not communicating as much anymore.

Managing relationships with stakeholders also emerged as a potential challenge. Scientist indicated that, at times, it was difficult to balance academic research with the changing needs of developers. For example, one scientist described their response to a developer's decision to change [research] plans. He said, "It's very difficult for you to adjust to it and to say, 'Okay, I'm going to scrap what I have been doing and do it the other way.' It's nearly impossible as a [researcher] to do that."

Lack of resources, namely funding and time, was identified as a critical constraint for MTPI moving forward. Succinctly put by one scientist:

I think the challenge is that everyone's so busy. I don't think there's a lack of will, and I think that if we could, we would meet more to figure out new approaches or spend more time and more efforts working on proposals to get this moving. 
Time constraints were also associated with the peer-review process. "Academic integrity and high-quality academic work is slow and it requires that things be properly reviewed," explained one scientist. This may cause tension at the development scale. Nearly all scientists and partners mentioned funding constraints. Some expressed the difficulty of integrating other researchers and expertise without additional funding. In one instance, plans to create synergies between MTPI projects never materialized due to lack of funding and human capital. In another example, funding constraints limited the ability to work with other interests, such as the local Passamaquoddy Tribe. Funding constraints had other more subtle effects as well. Without funding, researchers could only spend limited time on their tidal power research program. One scientist pointed out, "There hasn't been enough safety and security and resources for [MTPI researchers] to throw everything behind this." Instead, they need to put higher priority on research programs that generate funding support. In summing up the funding challenge, one scientist said, "Our goal should be to figure out how we are going to fund the research, because that's a core piece of this. If you don't have the money, you don't have the manpower." The broader issue of MTPI's future role "and how it would sustain itself" was a general concern of scientists and partners.

\section{$\underline{\text { Discussion }}$}

MTPI's approach to research and engagement provides a unique opportunity to examine how scientists from different disciplines and institutions and stakeholders from different sectors of 
society are building joint capacity to address societal concerns related to tidal energy development in Cobscook Bay, Maine. In sharing lessons learned from research on and participation in transdisciplinary sustainability science research, we examine how group structure and process lead to productive outcomes and substantive challenges. These findings offer practical guidance for scientists interested in carrying out similar interdisciplinary research and stakeholder engagement processes in other research contexts.

Informing interdisciplinary research

MTPI's framing of research extends beyond discipline-specific research and methods to the broadly comprehensive problem of sustainable energy development. MTPI's unique structure and process support this "holistic" mission and interdisciplinary approach. Specifically, MTPI's team building, shared problem awareness, and unified support of the group's philosophy and approach were critical to the transdisciplinary research process (Lang et al. 2012). MTPI's disciplinary team approach provides formal structure for organizing the core research components, but the informal non-hierarchical structure encourages mutual learning and respect. MTPI's name and mission statement provides group definition and a structure or "umbrella" for organizing MTPI research components. However, while our research suggests that these are key organizational components, process elements were also critical for maintaining the group's current cohesion and balanced approach and should be considered in the design and implementation of other transdisciplinary projects. 
MTPI has created a framework to manage and integrate group activity in a way that encourages on-going learning and action. Collaboration and mutual learning is a core component of MTPI's philosophy and is also a key aspect of transdisciplinary research (Lang et al. 2012). Rather than compartmentalized learning, MTPI allows for success in one's own discipline while at the same time creates opportunities for scientists to share ideas, learn from each other, inform each other's work, and create synergies between projects. This process is personally rewarding to the researchers and partners involved, leading to a higher level of commitment and sustained participation in the group's activities.

Despite positive outcomes, MTPI faces significant challenges for long-term support of interdisciplinary research, and these may have important implications for the design and implementation of interdisciplinary research in other contexts. First, if only some components of MTPI's larger project are funded moving forward, momentum could be lost, and the group could splinter. Although a recognized challenge, it will be important to seek future funding that continues to support MTPI's holistic mission. Second, continued interest and participation at a scale and level that is manageable is a critical to the success of transdisciplinary sustainability research (Lang et al. 2012). Further opportunities for learning and synergies should be supported for the long-term success of collaborative initiatives such as MTPI. Our research and experience suggest that one approach might be to use bimonthly meetings to share tangible results, rather than focus on dayto-day logistics. As research and development evolve, mechanisms will need to be in place to 
manage larger group activities, for example, more frequent individual team meetings or increased efforts to distribute meetings minutes to keep all groups and members informed. Graduate student involvement can also foster linkages between teams and is critical to training next generation scientists. Moving forward, it will be important for MTPI's process to maintain enough formal structure so that there are guiding goals and practices that give shape to the research, but that remains flexible enough to react and respond to emergent findings (van Kerkhoff 2013).

As MTPI moves forward, it will be important to consider how research-based knowledge is used to develop solution options for sustainable tidal energy development. MTPI seeks to reintegrate knowledge gained from the CBTEP that would allow for transferring and scaling up of usable solutions (Miller et al. 2013; Lang et al. 2012; Weik et al. 2012b). Specifically, MTPI aims to assess whether knowledge gained can be extrapolated to a new site and a second-generation device currently under development by ORPC. Applicability and transferability of knowledge generated in pursuit of solution options are important (Lang et al. 2012), and MTPI illustrates how a single case can provide enough evidence to inform the design other research programs and development projects globally.

Informing stakeholder engagement 
Using an iterative process of research and outreach, MTPI complemented their specific disciplinary methods (e.g., ethnographic research and biological surveys) with other processes (e.g., community outreach and technical symposiums). These processes that "do not traditionally fall under the category of 'research methods"' are "crucial" for integrating the research "into the social and political processes that an integrative study sits within (van Kerkhoff 2013)." Our research is embedded in the complex decision-making process for development of new tidal energy technologies in Maine. Commercialization of tidal energy could potentially provide direct environmental and social benefits such as clean energy and local jobs. However, little is known about the long-term impacts of tidal energy technology on the local environment and host communities. Making informed decisions about where tidal energy development may be environmentally appropriate and socially acceptable requires careful consideration of potential costs associated with development on coastal marine ecosystems and the local communities that depend on them.

Engaging with stakeholders affecting or affected by the decision-making process is important for enhancing the saliency, credibility, and legitimacy of knowledge produced (Cash et al. 2003) and improving linkages between research-based knowledge and action (van Kerkhoff and Lebel 2006). In our example, MTPI's integration of research and outreach, through formal and informal mechanisms, created transparency in the research process used to gather (and disseminate) information on potential impacts of tidal power technologies (e.g., fish turbine interactions). In the absence of transparency, the decision-making process risks not being able to harness knowledge for decision making (Cash et al. 2003). Instead, MTPI's process allowed diverse 
opportunity for stakeholders to inform and provide feedback on the research and for stakeholders to process, interpret, and use research-based knowledge generated.

Creating and maintaining effective feedback loops of knowledge through collaboration with diverse stakeholders in industry and government helped to avoid the "knowledge-first trap," defined as "endless collaborative research that continuously postpones the ultimate step of releasing outcomes" (Lang et al. 2012, p. 38). Instead MTPI embraced the notion of "researchingby-doing" (Lang et al. 2012). This participatory approach supported the coproduction of knowledge (Kates et al. 2001) and "inspired" action on the basis of MTPI's scientific research (Komiyama and Takeuchi 2011). MTPI scientists were invested in producing usable knowledge to move the tidal power industry forward on a more sustainable trajectory. This involved a commitment to generate information that could be used by regulators and developers to inform permitting and regulatory decisions. MTPI's intention to create usable knowledge positions them the interface of science and management, and MTPI acts as boundary organization (Guston 2001; Cash 2001) between research and implementation. Information flow across the boundary between industry and academia is made possible, in part, by ORPC's open and transparent process. ORPC's collaboration with MTPI has not involved secrecy or at least highly controlled and limited collaboration that may be typical of the commercialization process (Yarime 2011). Because of shared understanding or “balanced problem ownership" (Lang et al. 2012), MTPI did not exhibit many of the critical factors that could undermine continued participation. Circularities in MTPI's research process also enabled social learning and participants were engaged in on-going learning and action rather than in merely identifying a prescriptive solution (van Kerkhoff 2013). This approach allowed stakeholders to shape 
the direction of research and better link research to their needs (Johnson and Zydlewski 2012; Jansujwicz and Johnson 2013; Johnson et al. 2013). For example, through collaboration with industry and regulators, MTPI scientists developed protocols for environmental monitoring of MHK devices, and this "actionable knowledge" was incorporated into ORPC's adaptive management process and into 6-month progress reports submitted to FERC as mandated by the permitting process. The engaged research process enabled improvements in the use of research for future regulatory decision making and helped regulators become more comfortable with the research and development process (Jansujwicz and Johnson 2013).

MTPI's approach has also informed effective and efficient community engagement practices (Johnson et al. 2013). Formal and informal interaction with diverse community members including fishermen, local business owners, and community leaders has resulted in important outcomes. In some cases, trusted local voices became "spokespeople" for the research. In others, by knowing where scientists would be sampling and when they would be at the study sites, conflict between multiple uses of coastal ecosystems was avoided (for example, conflict between research gear and fixed fishermen's gear). Promoting dialog between scientists and the public may also serve to improve public understanding of MTPI's scientific findings and may have implications for social acceptability of tidal power development (Komiyama and Takeuchi 2011, 2006).

Enhanced understanding of stakeholder questions, concerns, and information needs also provides a better understanding of how emerging issues might be better represented in current 
and future research. At the same time, however, when stakeholder needs change (i.e., new technology design testing), academic scientists may not have the flexibility to change their research design. Indeed, academia, industry, and the public work within different timeframes, and this can strain relations. Understanding expectations and capacities of the different groups will be important to ensure that both parties get what they need from the collaborative process.

\section{Conclusion}

In evaluating MTPI's coordinated research agenda, we examine the group's organizational structure and process and the respective rewards and challenges this brings about. Our intent was not to provide a comprehensive set of principles for guiding transdisciplinary sustainability research, but rather to draw on empirical research and our experience to present exemplary opportunities and challenges faced in a concrete project that can be used to inform future practice.

Importantly, MTPI's structure and process allow for a productive combination of problem identification and analysis (i.e., what MTPI scientists refer to as "knowledge development") and problem solving (i.e., MTPI's approach to document, understand, and integrate stakeholder concerns and information needs into research, outreach, and development processes). This approach to research and outreach offers a generalizable framework for designing and conducting interdisciplinary integration and stakeholder engagement processes to bridge the gap between 
problem identification/analysis and decision making for the responsible development of tidal power. Lessons learned from the process of integrative collaborative research in Maine can offer guidance for other researchers interested in carrying out similar transdisciplinary sustainability science research in other contexts. 
Acknowledgements

The authors would like to thank MTPI scientists and stakeholders for generously sharing their time and perspectives on tidal power research and development. We would also like to thank Colleen Budzinski and Theodore Koboski for their assistance in the field and in preparing this manuscript. Special thanks to Ruth Hallsworth for her assistance with the figures. This research was conducted as part of the Sustainability Solutions Initiative, supported by National Science Foundation award EPS-0904155 to Maine EPSCoR at the University of Maine. 
Figures

Figure 1 MTPI organizational structure

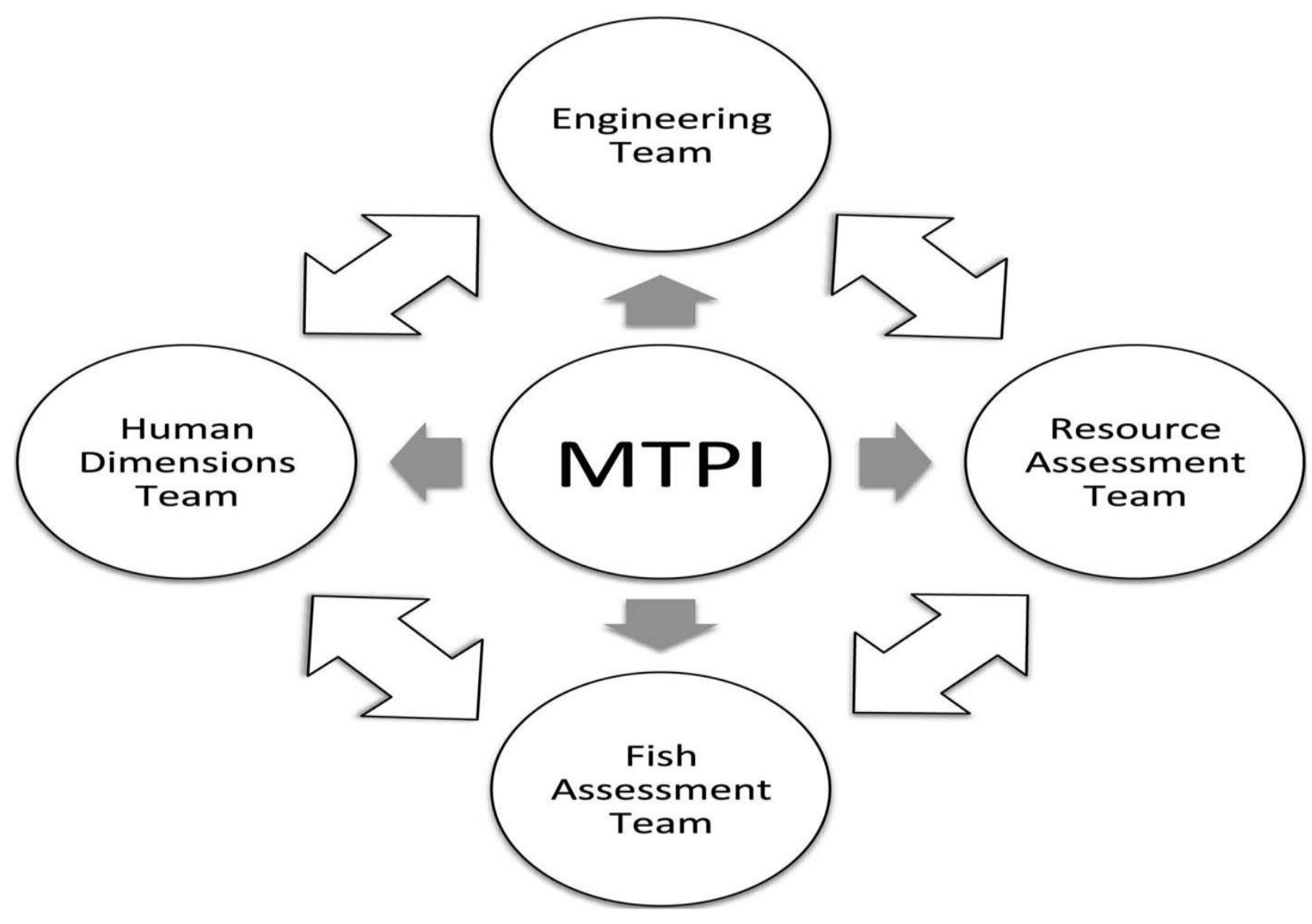


Figure 2 MTPI's approach to interdisciplinary research and stakeholder engagement

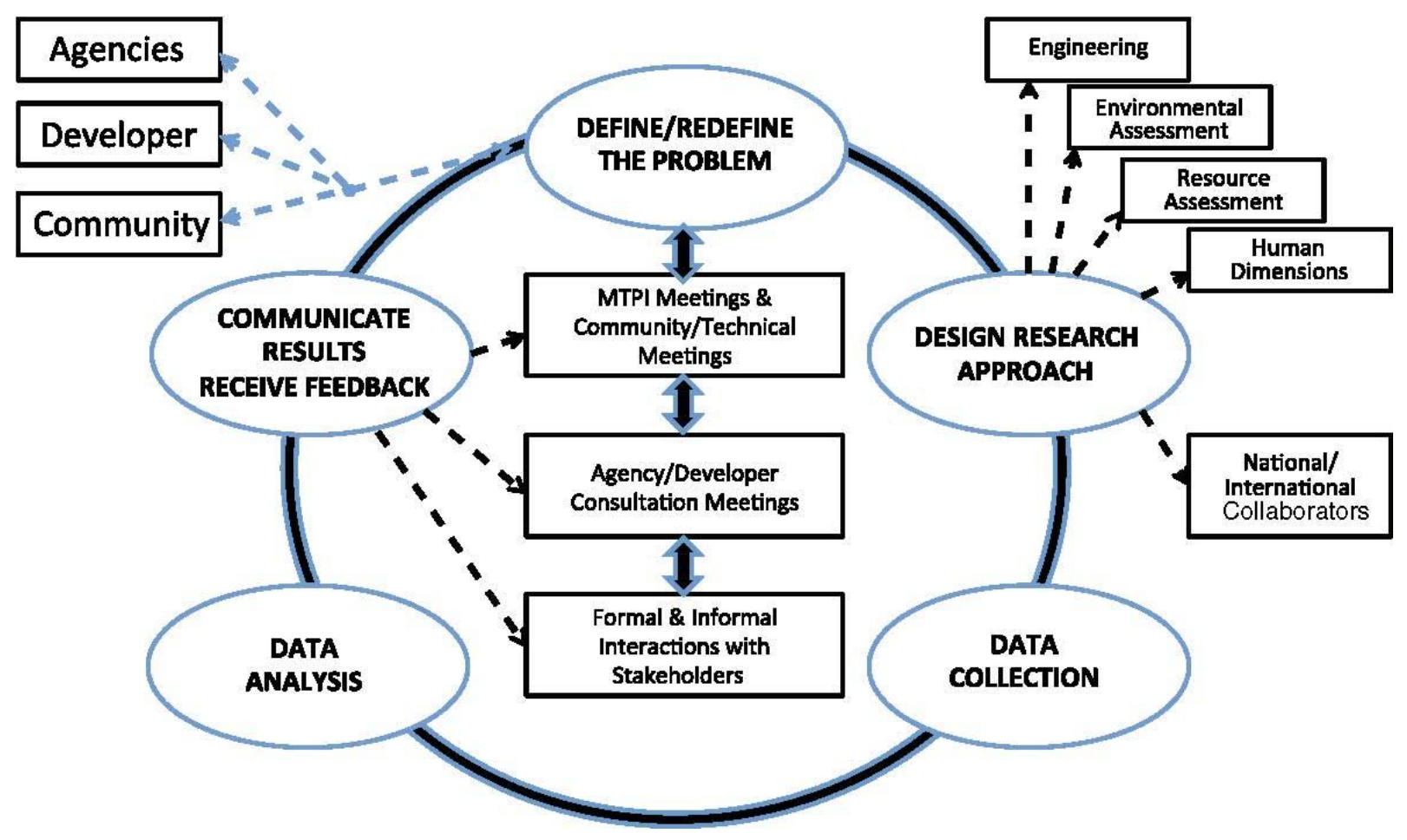




\section{References}

Anderson M, Teisl M, Noblet C (2012) Retrospective assessment to learn prospective stakeholder engagement: toward finding a voice for the future in sustainability science. Ecol Econ 84:1-6

Bell K, Lindenfeld L, Spears A, Teisl M, Leahy J (2013) Creating opportunities for improving lakefocused stakeholder engagement: knowledge-action systems, pro-environmental behavior, and sustainable lake management. Lakes Reserv Res Manage 18(1):5-14

Bernard RH (2006) Research methods in anthropology: qualitative and quantitative approaches. AltaMira Press, Lanham

Blackstock KL, Kelly GI, Horsey BL (2007) Developing and applying a framework to evaluate participatory research for sustainability. Ecol Econ 60:726-742

Brooks DA (2004) Modeling tidal circulation and exchange in Cobscook Bay, Maine. Northeastern National 11(2):23-50

Cada G, Ahlfrimm J, Bahleda M, Bigford T, Stavrakas SD, Hall D, Moursund R, Sale M (2007) Potential impacts of hydrokinetic and wave energy conversion technologies on aquatic environments. Fisheries 32:174-181

Cada G, Copping AE, Roberts J (2012) Ocean/tidal/stream power: identifying how marine and hydrokinetic devices affect aquatic environments. Hydroworld.com (Accessed June 10, 2012)

Cash DW (2001) In order to aid in diffusing useful and practical information: agricultural extension and boundary organizations. Sci Technol Human Values 26(4):431-453

Cash DW, Clark WC, Alcock F, Dickson NM, Eckley N, Guston DH, Jager J, Mitchell RB (2003) Knowledge systems for sustainable development. Proc Natl Acad Sci 100:8086-8091

Charmez K (2006) Constructing grounded theory: a practical guide through qualitative analysis. Sage, Thousand Oaks California

Clark W, Dickson N (2003) Sustainability science: the emerging research program. PNAS 100(14). doi:10.1073/pnas.1231333100

Corbin J, Strauss A (2008) Basics of qualitative research: techniques and procedures for developing grounded theory. Sage, Thousand Oaks California

DeWalt KM, DeWalt BR (2011) Participant observation: a guide for fieldworkers. Alta Mira Press, United Kingdom

Gardner SK (2013) Paradigmatic differences, power, and status: a qualitative investigation of faculty in one interdisciplinary research collaboration on sustainability science. Sustain Sci 8:241252

Glaser BG, Strauss AL (1967) The discovery of grounded theory: strategies for qualitative research. Aldine, Chicago

Guston DH (2001) Boundary organizations in environmental policy and science: an introduction. Sci Technol Hum Values 26:399-408

Hart D, Bell K (2013) Sustainability science: a call to collaborative action. Agric Resour Econ Rev 42(1):75-89

Hirsch Hadorn G, Bradley D, Pohl C, Rist S, Weismann U (2006) Implications of transdisciplinarity for sustainability research. Ecol Econ 60(2006):119-128. doi:10.1016/j.ecolecon.2005.12. 002 
Jansujwicz J, Johnson T (2013) Understanding and informing permitting decisions for tidal energy development using an adaptive management framework. Estuaries Coasts. doi:10.1007/ s12237-013-9678-0

Johnson T, Zydlewski G (2012) Research for the sustainable development of tidal power in Maine. Maine Policy Rev 21(1):58-64

Johnson TR, Jansujwicz JS, Zydlewski G (2013) Tidal power development in Maine: stakeholder identification and perceptions of engagement. Estuaries Coasts. doi:10.1007/s12237-0139703-3

Kates R, Clark W, Corell J, Hall M, Jaeger C, Lowe I, McCarthy J, Joachim Schellnhuber J, Bolin B, Dickson N, Faucheus S, Gallopin G, Gruebler A, Huntley B, Jager J, Jodha N, Kasperson R, Mabogunje A, Matson P, Mooney H, Moore B III, ORiordan T, Svedin U (2001) Sustainability science. Science 292(5517):641

Komiyama H, Takeuchi K (2006) Sustainability science: building a new discipline. Sustain Sci 1:1-6. doi:10.1007/s11625-0060007-4

Komiyama H, Takeuchi K (2011) Sustainability science: building a new academic discipline. In: Komiyama H, Takeuchi K, Shiroyama H, Mino T (eds) Sustainability science: a multidisciplinary approach. United Nations University, Tokyo, pp 22-34

Landon Maynard M, Schneider JA, McEntee J, Newberg E (2013) Suction caissons for cross-flow tidal power system. Proc ICE-Geotech Eng 166(2):99-110

Lang DJ, Weik A, Bergmann M, Stauffacher M, Martens P, Moll P, Swilling M, Thomas CJ (2012) Transdisciplinary research in sustainability science: practice, principals and challenges. Sustain Sci 7(Supplement 1):25-43. doi:10.1007/s11625-011-0149x

McCoy SK, Gardner SK (2012) Interdisciplinary collaboration on campus: five questions change: the magazine of higher learning (November-December 2012)

Miller TR, Wiek A, Sarewitz D, Robinson J, Olsson L, Kriebal D, Loorbach D (2013) The future of sustainability science: a solutions-oriented research agenda. Sustain Sci. doi:10.1007/ s11625-013-0224-6

Saldaña J (2009) The coding manual for qualitative researchers. Sage, Thousand Oaks California Shields MA, Wool D, Grist E, Kerr S, Jackson C, Harris R, Bell M, Beharie R, Want A, Osalusi E, Gibb S, Side J (2011) Marine renewable energy: the ecological implications of altering the hydrodynamics of the marine environment. Ocean Coast Manag 54:2-9

Spangenber J (2011) Sustainability science: a review, an analysis and some empirical lessons. Environ Conserv 38(3):275-287. doi:10. 1017/S0376892911000270

Strauss AC, Corbin JM (1990) Basics of qualitative research: grounded theory procedures and techniques. Sage, Thousand Oaks California

Talwar S, Weik A, Robinson J (2011) User engagement in sustainability research. Sci Public Policy 38(5):379-390. doi:10.103152/030234211X129603152667615

Urbina R, DeBree G, Cameron M, Peterson M, Kimball R (2013) Modeling and validation of a cross flow turbine using free vortex model and a modified dynamic stall model. J Renew Energy 50(84):662-669

van Kerkhoff $L$ (2013) Developing integrative research for sustain-ability science through a complexity principals-based approach. Sustain Sci. doi:10.1007/s11625-013-0203-y

van Kerkhoff L, Lebel L (2006) Linking knowledge and action for sustainable development. Ann Rev Environ Resour 31:445-477 
Viehman H, Zydlewski G (2014) Fish interaction with a commercial-scale tidal energy device in a field setting. Estuaries Coasts. doi:10.1007/s12237-014-9767-8

Viehman H, Zydlewski G, McCleave J, Staines G (2014) Using acoustics to understand fish presence and vertical distribution in a tidally dynamic region targeted for energy extraction. Estuaries Coasts. doi:10.1007/s12237-014-9776-7

Weik A, Fariloi F, Fukushi K, Yarime M (2012a) Sustainability science: bridging the gap between science and society. Sustain Sci 7(Supplement 1):1-4. doi:10.1007/s11625-011-0154-0

Weik A, Ness B, Schweizer-Ries P, Brand F, Farioli F (2012b) From complex systems analysis to transformational change: a comparative appraisal of sustainability science projects. Sustain Sci 7(Supplement 1):5-24. doi:10.1007/s11625-011-0148-y

Xu D, Xue H (2011) A numerical study of horizontal dispersion in a macro tidal basin. Ocean Dyn 61(5):623-637

Yarime M (2011) Exploring sustainability science: knowledge, institutions and innovation. In: Komiyama H, Takeuchi K, Shiroyama H, Mino T (eds) Sustainability science: a multidisciplinary approach. United Nations University, Tokyo, pp 98-111 